\title{
Economic Load Dispatch in Power System using Genetic Algorithm
}

\author{
Bishnu Sahu \\ Department Of Electrical \\ Engnieering \\ Kiit University
}

\author{
Avipsa Lall \\ Department Of Electrical \\ Engnieering \\ Kiit University
}

\author{
Soumya Das \\ Department Of Electrical \\ Engineering \\ B.P.U.T.
}

\author{
T. Manoj Patra \\ Department Of Electrical \\ Engnieering \\ Kiit University
}

\begin{abstract}
Evolutionary algorithms are becoming an important aspect of artificial intelligence and are successfully applied to a variety of optimization problems. This paper presents genetic algorithm and quadratic programming concepts in solving economic load dispatch in which the total cost of generating power is minimized with a valve point loading effect while satisfying the load demand irrespective of transmission line losses. This work aims in modeling the economic load dispatch problem with transmission loss and is being applied to the test systems i.e. IEEE 14 BUS and IEEE 30 BUS using MATLAB.
\end{abstract}

\section{Keywords}

Genetic algorithm, Quadratic Programming, Economic Load Dispatch

\section{INTRODUCTION}

Electrical power systems are designed and operated to meet the continuous variation of power demand. In power system, minimization of operation cost is very important. Economic load dispatch (ELD) is a method to schedule the power generator outputs with respect to the load demands and to operate the power system most economically or in other words the main objective is to allocate the optimal power generation of different units at the lowest cost possible while meeting all system constraints [1].

Over the years, many efforts have been made to solve the ELD problem, incorporating different kinds of constraints or multiple objectives through various mathematical programming and optimization techniques. The conventional methods include Newton-Raphson method, Lambda Iteration method, Base point and Participation Factor method, Gradient method etc [2]. However these classical dispatch algorithms require the incremental cost curves to be monotonically increasing or piece-wise linear [3]. To solve economic dispatch problem effectively, most algorithms require the incremental cost curves to be of monotonically smooth increasing nature and continuous [4-7].

To obtain accurate dispatch results, the approaches without restriction on the shape of fuel cost functions are necessary [8-9]. Most of conventional methods suffer from the convergence problem, and always get trap in the local minimum. Moreover, some techniques face the dimensionality problem especially when solving the large-scale system

In recent years, one of the most promising research fields has been "Evolutionary Techniques", an area utilizing analogies with nature or social systems. Evolutionary techniques are finding popularity within research community as design tools and problem solvers because of their versatility and ability to optimize in complex multimodal search spaces applied to non-differentiable objective functions. Several modern heuristic tools have evolved in the last two decades that facilitate solving optimization problems that were previously difficult or impossible to solve.

In this paper two different approaches of evolutionary algorithms have been executed and compared i.e. economic load dispatch using quadratic programming and with genetic algorithm for the two test systems i.e. IEEE 14 BUS \& IEEE 30 BUS to show the effectiveness of genetic algorithm.

\section{PROBLEM FORMULATION}

This section deals with the formulation of economic load dispatch problem where the objective function has to be minimized depending upon its equality and inequality constraints. Transmission loss plays a major factor and affects the optimum dispatch of generation. The economic load dispatch problem considering the transmission line loss $\mathrm{P}_{\mathrm{L}}$ is formulated below.

Objective function:--

$$
\operatorname{Min} F=\sum_{i=1}^{m} F_{i}\left(P_{g i}\right)
$$

Subject to

$$
\begin{aligned}
& \sum_{i=1}^{m} P_{g i}=\sum_{i=1}^{m} P_{D i}+P_{L} \\
& \left|P_{i_{\text {min }}}\right| \leq\left|P_{i}\right| \leq\left|P_{i_{\text {max }}}\right|
\end{aligned}
$$


where $F_{i}\left(P_{g i}\right)$ represents the cost function of generating units and is formulated as :

$$
F_{i}\left(P_{g i}\right)=a_{i}\left(P_{g i}^{2}\right)+b_{i}\left(P_{g i}\right)+c_{i}
$$

For accurate analysis of ELD, the fuel cost function is modeled as ripple curve and the effect of value point loading is considered and hence eqn (4) is being modified as :-

$$
\begin{aligned}
& \quad F_{i}\left(P_{g i}\right)=a_{i}\left(P_{g i}^{2}\right)+b_{i}\left(P_{g i}\right)+c_{i}+ \\
& d_{i}\left(\sin \left(P_{g i}^{\min }-P_{g i}\right)\right)
\end{aligned}
$$

where $a_{i}, b_{i}, c_{i}$ are cost coefficients.

The eqn (2) represents the equality constraint where the generation of power must satisfy the load demand irrespective of line loss.

The eq (3) represents the inequality constraint that shows the minimum and maximum limits of power generation by the units where

$$
\begin{aligned}
& P_{i \min }=\text { minimum } \text { power } \\
& P_{i \max }=\text { maximum } \text { power }
\end{aligned}
$$

\subsection{DERIVATION OF TRANSMISSION LOSS FORMULAE}

To achieve the true economic load dispatch, transmission losses must be taken into account. In this section a transmission loss formulae has been derived in terms of generating power. The power outputs of the $\mathrm{N}$ generating units at a particular time period have to satisfy the power balance constraint and operating limit constraints [9]-[10]. For arbitrary free unit power outputs $P_{i}, P_{i, \text { low }} \leq P_{i} \leq P_{i, \text { high }}, i=1 \ldots R-1, R+1 \ldots N$, it is assumed that the R-th reference unit power output is constrained by the power balance equation as:

$\mathrm{P}_{\mathrm{R}}=\mathrm{P}_{\mathrm{D}}+\mathrm{P}_{\mathrm{L}}-\sum_{\substack{i=j \\ i \neq R}}^{N} P_{i}$

The transmission loss $\mathrm{P}_{\mathrm{L}}$ can be written in terms of $\mathrm{P}_{\mathrm{R}}$ :

$\mathrm{P}_{\mathrm{L}}=\sum_{i=1}^{N}\left(\sum_{\substack{j=1 \\ j \neq R}}^{N}\left(P_{i} B_{i j} P_{j}\right)+\left(P_{i} B_{i R} P_{i}\right)\right)+$

$\sum_{\substack{i=1 \\ i \neq R}}^{N}\left(B_{i 0} P_{i}\right)+B_{R 0} P_{R}+B_{00}$

$\mathrm{P}_{\mathrm{L}}=\sum_{\substack{i=1 \\ i \neq R}}^{N} \sum_{\substack{j=1 \\ j \neq R}}^{N}\left(P_{i} B_{i j} P_{j}\right)+\sum_{\substack{j=1 \\ j \neq R}}^{N}\left(P_{R} B_{R j} P_{j}\right)+$

$\sum_{\substack{i=1 \\ i \neq R}}^{N}\left(P_{i} B_{i R} P_{R}\right)+\left(P_{R} B_{R R} P_{R}\right)+\sum_{\substack{i=1 \\ i \neq R}}^{N}\left(B_{i 0} P_{i}\right)+$

$B_{R 0} P_{R}+B_{00}$

$\mathrm{P}_{\mathrm{L}}=\mathrm{P}_{\mathrm{R}}\left[\sum_{\substack{j=1 \\ j \neq R}}^{N}\left(B_{R j} P_{j}\right)+\sum_{\substack{i=1 \\ i \neq R}}^{N}\left(P_{i} B_{i R}\right)+B_{R 0}\right]+$

$\left[P_{R} B_{R R} P_{R}\right]+\left[\sum_{\substack{i=1 \\ i \neq R}}^{N} \sum_{\substack{j=1 \\ j \neq R}}^{N}\left(P_{i} B_{i j} P_{j}\right)+\sum_{\substack{i=1 \\ i \neq R}}^{N}\left(B_{i 0} P_{i}\right)+\right.$

$\left.B_{00}\right]$
Where, $\mathrm{A}=\mathrm{B}_{\mathrm{RR}}$

$$
\begin{gathered}
\mathrm{B}=\sum_{\substack{j=1 \\
j \neq R}}^{N}\left(B_{R j} P_{j}\right)+\sum_{\substack{i=1 \\
i \neq R}}^{N}\left(P_{i} B_{i R}\right)+B_{R 0} \\
\mathrm{C}=\sum_{\substack{j=1 \\
j \neq R}}^{N}\left(B_{R j} P_{j}\right)+\sum_{\substack{i=1 \\
i \neq R}}^{N}\left(P_{i} B_{i R}\right)+B_{R 0}
\end{gathered}
$$

Substituting $\mathrm{P}_{\mathrm{L}}$ in eqn (6) we get,

$\mathrm{P}_{\mathrm{D}}+\mathrm{A}\left(\mathrm{P}_{\mathrm{R}}^{2}\right)+\mathrm{B}\left(\mathrm{P}_{\mathrm{R}}\right)+\mathrm{C}-\sum_{\substack{i=1 \\ i \neq R}}^{N} P_{i}-\mathrm{P}_{\mathrm{R}}=0$

$\mathrm{A}\left(\mathrm{P}_{\mathrm{R}}^{2}\right)+(\mathrm{B}-1) \mathrm{P}_{\mathrm{R}}\left[\mathrm{C}+\mathrm{PD}-\sum_{\substack{i=1 \\ i \neq R}}^{N} P_{i}\right]=0$

The roots of the quadratic eqn (8) provide the allocation vector which comprises of dispatching power of each generator connected in the system. The eqn (8) has been used in economic load dispatch using genetic algorithm and quadratic programming to find out the dispatching power and the total cost of the objective function.

\section{OVERVIEW OF ARTIFICIAL TECHNIQUE}

Population based optimization algorithms find near optimal solutions to the difficult optimization problems by motivation from nature and modified by applying the operators on the solutions depending on the information of the fitness moving towards the better solution region of the search space. The two important classes of population based optimization algorithms are evolutionary algorithm and swarm intelligence based algorithm. The first approach is quadratic programming (QP) which is used to solve linear constrained optimization problem. The second approach is genetic algorithm GA is widely used as an optimization tool and is based on genetic science and natural selection, it attempts to simulate the phenomenon of natural evolution at genotype level while evolutionary strategies and evolutionary programming simulate the phenomenon of natural evolution at a phenotype level.

\subsection{QUADRATIC PROGRAMMING}

Quadratic objective function with linearly constraint optimization problem is called as quadratic program. Quadratic programming is an efficient optimization technique to trace the global minimum if the objective function is quadratic and the constraints are linear. It is used recursively from the lowest incremental cost regions to high regions to find the optimum location. Once the limits are obtained and the data are rearranged in such a manner that the incremental cost limits of all the plants are in ascending order. The general quadratic program can be written as:--

$$
\operatorname{Min} f(x)=c x+0.5 x^{T} Q x
$$

Subject to

$$
\begin{gathered}
A x \leq b \\
x \geq 0
\end{gathered}
$$

Now $\mathrm{PL}=\mathrm{A}\left(\mathrm{P}_{\mathrm{R}}^{2}\right)+\mathrm{B}\left(\mathrm{P}_{\mathrm{R}}\right)+\mathrm{C}$ 
Where $\mathrm{c}$ is an $\mathrm{n}$ dimensional row vector describing the coefficients of the objective function and $\mathrm{Q}$ is an $\mathrm{nXn}$ symmetric matrix describing the coefficients of the quadratic terms. The decision variables are denoted by $\mathrm{x}$ and $\mathrm{A}$ is a matrix of $\mathrm{mXn}$ representing constraints of the model and $b$ is a column vector denoting right hand side coefficients.

\subsection{GENETIC ALGORITHM}

Traditional optimization methods such as those described are by far the most common optimization tool used in the industry. However, these techniques can encounter some difficulties such as getting trapped in local minima, increasing computational complexity and being not applicable to certain objective functions. This calls for developing a new class of solution methods that can overcome these limitations. Heuristic optimization is fast nascent tools that can overcome most of the shortcomings found in derivative based techniques.In 1975 Holland first used the concepts of real world to solve the search and optimization problem and invented GA as a power tool in its "Adaptation in natural and artificial systems"[10]. Main attraction of GA is its simple concept that is both easy to implement and computationally efficient. GA has a flexible and well balanced mechanism to enhance exploration and exploitation abilities. GA can be viewed as a generalpurpose search method, an optimization method, or a learning mechanism, based loosely on Darwinian principles of biological evolution, reproduction and "the survival of the fittest" [11-12]. GA maintains a set of candidate solutions called population and repeatedly modifies them. At each step, the GA selects individuals from the current population to be parents and uses them to produce the children for the next generation. In general, the fittest individuals of any population tend to reproduce and survive to the next generation, thus improving successive generations. However, inferior individuals can, by chance, survive and also reproduce.GA is well suited to and has been extensively applied to solve complex design optimization problems because it can handle both discrete and continuous values. The flowchart depicts the behaviour of genetic algorithm.

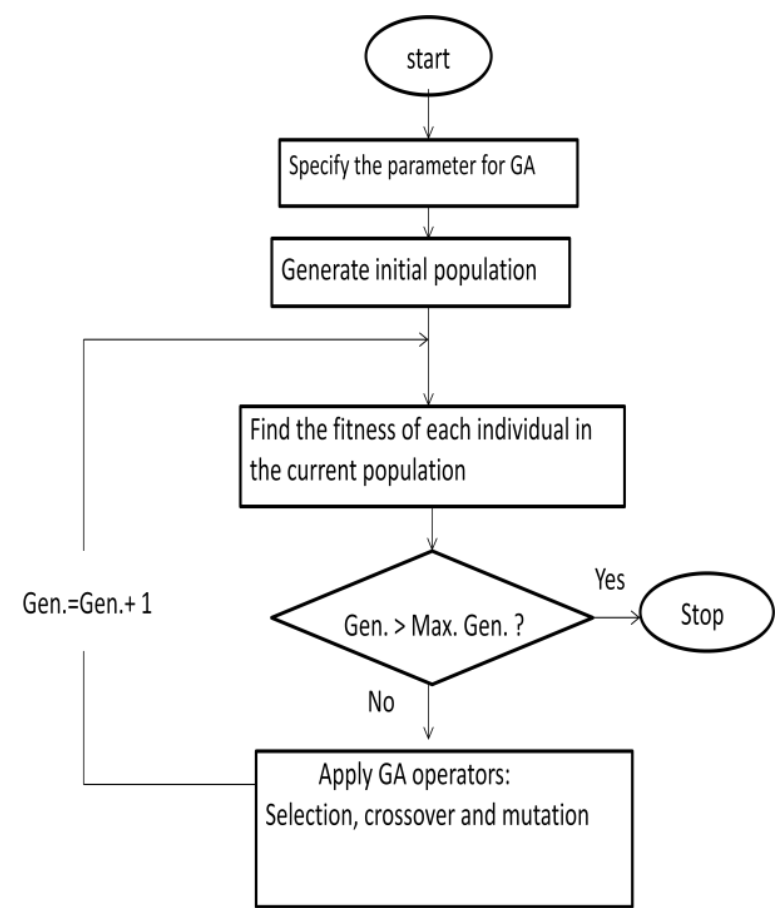

\subsection{ECONOMIC LOAD DISPATCH USING GA}

Step 1. Initialization

Initialize population size, maximum generation, stall time limit and read the cost coefficients and $\mathrm{B}$ coefficients.

Step 2. Formation of population

The initial power search for each generator can be obtained by

$$
\mathrm{P}_{\mathrm{i}}^{\mathrm{j}}=\mathrm{P}_{\mathrm{i}}^{\min }+\left\{\left(\mathrm{P}_{\mathrm{i}}^{\max }-\mathrm{P}_{\mathrm{i}}^{\min }\right) /\left(2^{1}-1\right)\right\}^{*} \mathrm{~b}_{\mathrm{i}}^{\mathrm{j}}
$$

Where,

$$
\begin{aligned}
& \mathrm{i}=\text { number of generator } \\
& \mathrm{j}=\text { number of generation }
\end{aligned}
$$

Step 3. Evaluate the fitness function.

The incremental transmission losses denoted as ' $\mathrm{B}$ ' is calculated as per formula the given below and determines the best fitness and mean fitness values.

Step 4. Apply genetic operators

Parent individuals are selected using 'Roulette Wheel' selection procedure and single point crossover is used and finally mutation operator is used for regaining the lost characteristics during the process.

Step 5. Repeat the step 3 and step 4 until the process has been converged or it satisfies the stopping criteria. 


\section{RESULT AND DISCUSSIONS}

In this paper two case studies are examined to confirm the effectiveness of GA in optimizing economic load dispatch problem. The Case-1 uses an IEEE 14 BUS test system having 5 generating units while Case 2 uses an IEEE 30 BUS test system with 6 generating units whose cost coefficients and the loss coefficients are given in Table 1 and Table 2 respectively.

Table 1. Cost coefficients

\begin{tabular}{|c|c|c|c|c|}
\hline $\begin{array}{c}\text { TEST } \\
\text { SYSTEM }\end{array}$ & BUS & $\mathbf{a}$ & b & c \\
\hline \multirow{5}{*}{ 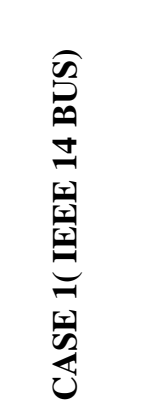 } & 1 & 0.0016 & 2 & 150 \\
\hline & 2 & 0.0100 & 2.5 & 25 \\
\hline & 3 & 0.0625 & 1 & 0 \\
\hline & 6 & 0.0083 & 3.25 & 0 \\
\hline & 8 & 0.025 & 3 & 0 \\
\hline \multirow{7}{*}{ 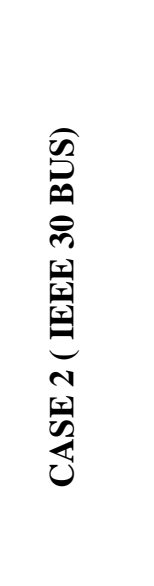 } & BUS & $\mathrm{a}$ & $\mathrm{b}$ & $\mathrm{c}$ \\
\hline & 1 & 0.00375 & 2 & 0 \\
\hline & 2 & 0.0175 & 1.75 & 0 \\
\hline & 5 & 0.0625 & 1 & 0 \\
\hline & 8 & 0.0083 & 3.25 & 0 \\
\hline & 11 & 0.025 & 3 & 0 \\
\hline & 13 & 0.025 & 3 & 0 \\
\hline
\end{tabular}

Table 2. Loss Coefficients

\begin{tabular}{|c|c|c|c|c|c|}
\hline \multicolumn{2}{|c|}{$\begin{array}{c}\text { TEST } \\
\text { SYSTEM }\end{array}$} & \multicolumn{4}{|c|}{ LOSS COEFFICIENTS X $\left(10^{-4}\right)$} \\
\hline \multirow{5}{*}{ 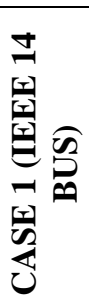 } & 2.1 & 8.5 & 6 & 2 & 2 \\
\hline & 8.0 & 1.8 & -6 & 5.1 & 2 \\
\hline & 6.0 & 6 & 4.8 & -1.3 & -1.6 \\
\hline & 2 & 5 & -1.3 & 2.18 & -2.51 \\
\hline & 2 & 2 & -1.6 & -2.51 & 1.4 \\
\hline \multicolumn{2}{|c|}{$\begin{array}{c}\text { TEST } \\
\text { SYSTEM }\end{array}$} & \multicolumn{4}{|c|}{ LOSS COEFFICIENTS X $\left(10^{-4}\right)$} \\
\hline
\end{tabular}

\begin{tabular}{|c|c|c|c|c|c|c|}
\hline \multirow{6}{*}{ 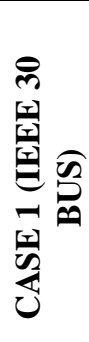 } & 2 & 1 & 3 & -1.1 & 1.2 & 1.3 \\
\hline & 1.09 & 1 & 1.0 & -1.9 & 5 & 8 \\
\hline & 3 & 1 & 3.14 & -1.55 & -5 & -2 \\
\hline & -0.1 & -1 & -1.5 & 2.98 & 5.5 & 1.1 \\
\hline & 1.2 & 5 & -5 & 5.5 & 1.3 & 5 \\
\hline & 1.3 & 8 & -2 & 1.14 & 5 & 1.2 \\
\hline
\end{tabular}

\section{Case 1:- IEEE 14 BUS TEST SYSTEM}

Upon optimization of economic load dispatch of IEEE 14 BUS test system using genetic algorithm provides better result than that of quadratic programming.

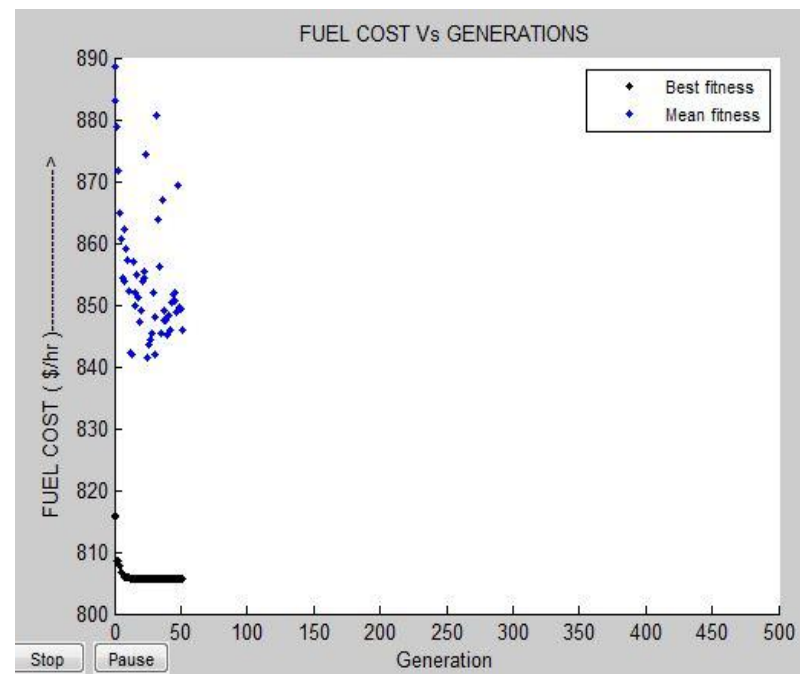

Fig 1: Fuel cost of IEEE 14 BUS test system

Fig 1 provides the best fitness as well as the mean fitness of fuel cost in different generations in GA. The value of best fitness is $805.552 \$ / \mathrm{hr}$ i.e. the total expenditure of producing the dispatched power to satisfy the load demand while the $860.7520 \$ / \mathrm{hr}$ is the total fuel cost in optimization with quadratic programming. 


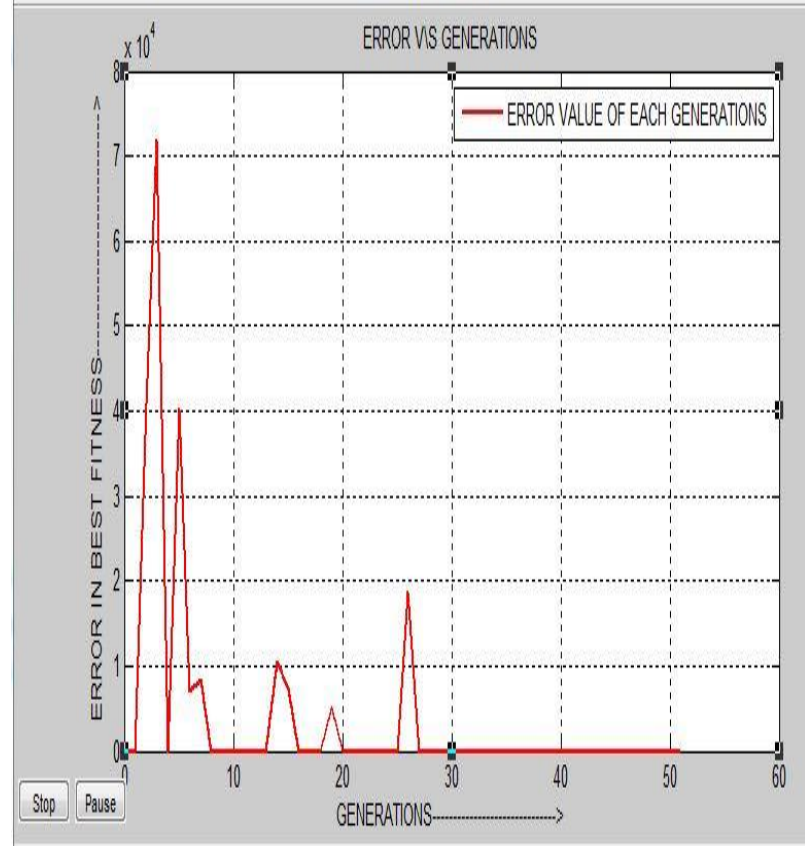

Fig 3: Convergence graph for IEEE 14 BUS test system.

The above graph shows the difference of best fitness values in each generation. Beyond $30^{\text {th }}$ generations the difference of best fitness comes to zero that indicates a fast convergence in this algorithm.

\section{Case 2: IEEE 30 BUS TEST SYSTEMS}

Optimization of cost function for IEEE 30 BUS test system has been evaluated by using GA and QP. The total fuel cost using GA is $18096.2 \$ / \mathrm{hr}$ and total fuel cost in QP is $18362.5 \$ / \mathrm{hr}$.

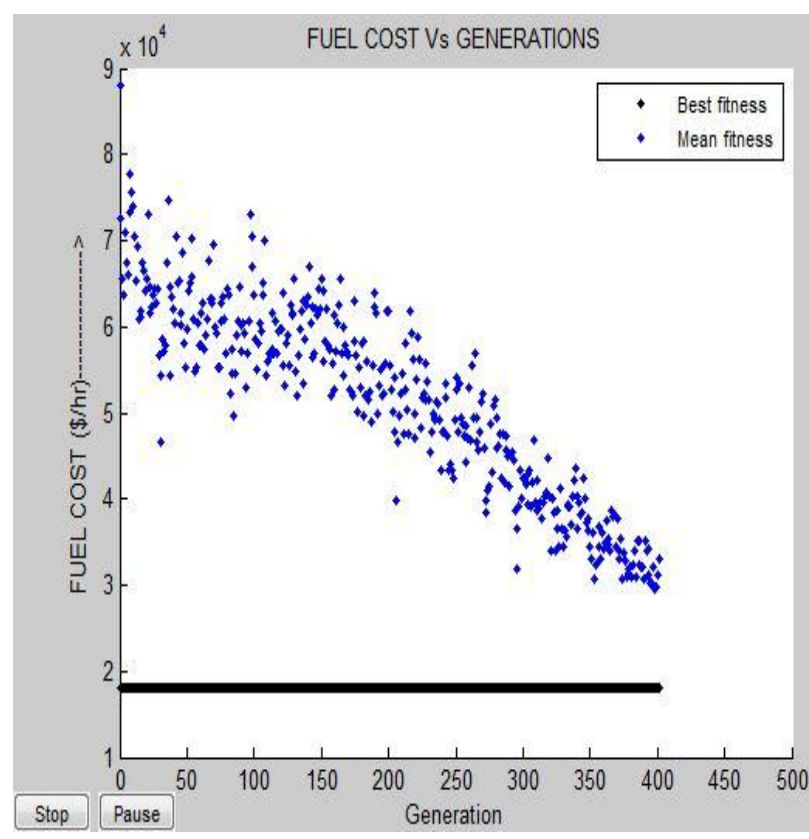

Fig 2: Fuel cost of IEEE 30 BUS test system

The above graph clearly indicates that the best fitness for each generation remains same throughout the total generations denoted by a straight line and the mean fitness is shown by dotted lines. The dispatched power and the detailed comparison of economic load dispatch using two evolutionary algorithms i.e. using GA and QP is shown below.

Table 3. Comparison of ELD in GA \& QP

\begin{tabular}{|c|c|c|c|c|c|}
\hline $\begin{array}{c}\text { TEST } \\
\text { SYSTEM }\end{array}$ & BUS & \multicolumn{2}{|c|}{$\begin{array}{l}\text { DISPATCHED } \\
\text { POWER (MW) }\end{array}$} & \multicolumn{2}{|c|}{$\begin{array}{c}\text { FUEL } \\
\operatorname{COST}(\$ / h r)\end{array}$} \\
\hline \multirow{6}{*}{ 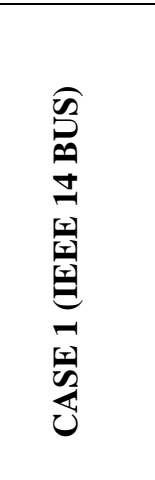 } & & QP & GA & $\mathrm{QP}$ & GA \\
\hline & 1 & 200 & 199.8 & \multirow{5}{*}{$\begin{array}{l}860.7 \\
520\end{array}$} & \multirow{5}{*}{805.55} \\
\hline & 2 & 25.79 & 24.28 & & \\
\hline & 3 & 15 & 15.77 & & \\
\hline & 6 & 10 & 10.41 & & \\
\hline & 8 & 10 & 10.48 & & \\
\hline \multirow{8}{*}{ 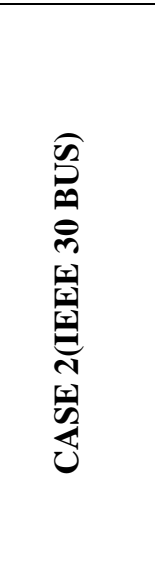 } & BUS & $\begin{array}{l}\text { DISP } \\
\text { POW }\end{array}$ & $\begin{array}{l}\Gamma \mathrm{CHED} \\
(\mathrm{MW})\end{array}$ & $\mathrm{CO}$ & $\begin{array}{l}\mathrm{JEL} \\
\Gamma(\$ / \mathrm{hr})\end{array}$ \\
\hline & & $\mathrm{QP}$ & GA & $\mathrm{QP}$ & GA \\
\hline & 1 & $\begin{array}{c}13.35 \\
97\end{array}$ & $\begin{array}{c}13.339 \\
1\end{array}$ & \multirow{6}{*}{$\begin{array}{l}18362 \\
.2\end{array}$} & \multirow{6}{*}{$\begin{array}{l}18096 . \\
5\end{array}$} \\
\hline & 2 & 10 & 10.00 & & \\
\hline & 5 & 39.98 & 39.98 & & \\
\hline & 8 & 58.28 & 58.358 & & \\
\hline & 11 & 40 & 40 & & \\
\hline & 13 & 125 & 125.11 & & \\
\hline
\end{tabular}

\section{CONCLUSION}

In this paper an attempt has been made to adopt the use of genetic algorithm and quadratic programming in economic load dispatch. Even though, excellent advancements have been made in classical methods, they suffer in handling qualitative constraints, poor convergence, may get stuck to local optimum, they become too slow if the number of variables are more and computationally more complex. Whereas, the major advantages of the artificial techniques are relatively versatile for handling various qualitative constraints in a simplest manner. In this paper an effort has been modeled to compare the artificial intelligence approach and arrived at a better solution which has a better ability to save the fuel cost and computational time. 


\section{REFERENCES}

[1] Wood A. J. and Wollenberg B. F., "Power generation, operation and control", John Wiley \& Sons, New York. 1984.

[2] B. H. Chowdhury and S. Rahman, "A review of recent advances in economic dispatch," IEEE Transactions on Power Systems, vol. 5, no. 4, pp. 1248-1259, November 1990.

[3] Sinha Nidul, Chakrabarthi R. and Chattopadhyay P. K.. "Evolutionary programming techniques for economic load dispatch", IEEE Transactions on evolutionary computation, Vol.7, pp.83 - 94, 2003

[4] H.W. Dommel, "Optimal power dispatch", IEEE Transactions on Power Apparatus and Systems, PAS93 No. 3, pp. 820-830, 1974.

[5] C.O. Alsac, J. Bright, M. Paris, and Stott, "Developments in LP -based optimal power flow, IEEE Transaction of Power Systems", Vol. 5 No. 3, pp. 697-711, 1990.

[6] J. Nanda, D.P. Kothari, S.C. Srivastava, "New optimal power-dispatch algorithm using fletcher's quadratic programming method", IEE Proceedings, Vol. 136 No. 3, pp. 153-161, 1989.

[7] A. Jiang and S. Ertem, "Economic dispatch with non-monotonically increasing incremental cost units and transmission system losses",IEEE Transactions on Power Systems, vol. 10, no. 2, pp. 891-897, May 1995.

[8] H. T. Yang, P. C. Yang and C. L. Huang, "Evolutionary Programming Based Economic Dispatch For Units With Non -smooth Fuel Cost Functions," IEEE Transactions on Power Systems, Vol. 11, No. 1, pp. 112-118, 1996.
[9] T. Jayabarathi, G. Sadasivam and V. Ramachandran, "Evolutionary programming based economic dispatch of generators with prohibited operating zones," Electric Power Systems Research, Vol. 52, No. 3, pp. 261-266, 1999.

[10]D. E. Goldberg, "Genetic Algorithms in Search, Optimization and Machine Learning". AddisonWesley, 1989.

[11]H. H. Happ, "Optimal power dispatch-A comprehensive survey", IEEE Trans. Power Apparat. Syst., vol. PAS-90, pp. 841-854, 1977.

[12]B. H. Chowdhury and Rahman, "Recent advances in economic dispatch", IEEE Trans. Power Syst., no. 5, pp. 1248-1259, 1990.

\section{AUTHORS' PROFILE}

BISHNU PRASAD SAHU Received B-tech in Electrical and Electronics Engineering from Roland Institute of Technology, Berhampur in 2011, currently pursuing Mtech with specialization in Power and Energy System from KIIT University, Bhubaneswar (2011-2013)

AVIPSA LALL- Received B-tech in Electrical and Electronics Engineering from Roland Institute of Technology, Berhampur in 2011, currently pursuing Mtech with specialization in Power and Energy System from KIIT University, Bhubaneswar (2011-2013)

SOUMYA RANJAN DAS- Presently working as an associate professor in the department of Electrical and Electronics Engineering in Roland Institute of Technology, BPUT, and Odisha, India.

T.MANOJ KUMAR PATRA- Received B-tech in Electrical and Electronics Engineering from Roland Institute of Technology, Berhampur in 2011, currently pursuing M-tech with specialization in Power and Energy System from KIIT University, Bhubaneswar (2011-2013) 